\title{
Síntesis de capas buffer para celdas solares de película delgada
}

\author{
William Andres Vallejo Lozada* \\ Universidad América, Avda. Circunvalar No 20-53, Bogotá, Colombia
}

Fecha de Entrega: Marzo 14 de 2012

FECha de EVAluación: ABRIL 4 DE 2012

FEChA DE APROBACIÓN: MAYO 3 DE 2012

\begin{abstract}
Resumen En este trabajo se hace una revisión del funcionamiento y estado actual de las capas buffer libres de Cadmio; componentes esenciales de las celdas solares de tecnología de película delgada. Se hace especial énfasis en diferentes tipos de compuestos que pueden ser utilizados como capas buffer y el proceso Chemical Bath Deposition como el método de síntesis más utilizado en la actualidad a escala laboratorio y a escala industrial para la fabricación de este tipo de recubrimientos.
\end{abstract}

Palabras Clave: celdas solares, capas buffer, película delgada.

\begin{abstract}
This article reviews the function and current status of cadmiumfree buffer layers. These are essential components of solar cells of thin layer technology. We emphasize on different types of components that can be used as buffer layers and on the Chemical Bath Deposition process as the synthesis method most used currently in the laboratories and industries for manufacturing this type of coating.
\end{abstract}

Keywords: solar cells, buffer layers, thin layer.

* Químico Universidad Nacional de Colombia. Doctor en Ciencias, Universidad Nacional de Colombia. Áreas de interés: celdas solares, fotocatálisis e instrumentación virtual. wavallejol@gmail.com 


\section{Introducción}

En la actualidad la producción energética mundial de las energías renovables no es grande, sin embargo este tipo de energías ha tenido un crecimiento significativo en los últimos años. Por un lado la generación a través de sistemas fotovoltaicos interconectados tuvo un crecimiento anual promedio cercano al $60 \%$, mientras que durante este mismo periodo los biocombustibles presentaron un incremento superior al $40 \%$ anual; esta tendencia se ha mantenido desde el año 2000. Otras tecnologías, como la biomasa y la geotérmica presentaron un crecimiento anual promedio entre el $3 \%$ y el $5 \%$. Con base en estos niveles de crecimiento en la capacidad de producción energética cabe esperar que para el futuro la participación de la generación fotovoltaica en el mercado energético mundial sea importante $[1]$.

En el mercado de la energía solar fotovoltaica existen diferentes tipos de tecnologías que ofrecen diferentes características y ventajas; actualmente la tecnología de Silicio (conocida como tecnología de primera generación) es la tecnología más utilizada para la fabricación de módulos fotovoltaicos dominado el mercado mundial, sin embargo esta tipo de tecnología requiere grandes cantidades de material de elevada pureza haciéndola muy cara. La segunda tecnología en importancia es la tecnología de película delgada (conocida como tecnología de segunda generación), este tipo de tecnología requiere cantidades mínimas de material en comparación con la tecnología de Silicio, lo que permite fabricar módulos fotovoltaicos a costos significativamente menores que sus homólogos de Silicio, en los últimos años la tecnología de película delgada ha presentado un importante crecimiento gracias a sus reducidos costos de producción [2].

A pesar de que las celdas solares, basadas en película delgada, presentan bajos costos de producción y gran estabilidad, este tipo de tecnología tienen una limitante desde el punto de vista medio ambiental debido a que incorporan en su estructura, una delgada capa de CdS (50 nm); un material altamente tóxico [3], que es peligroso para el hombre y el medio ambiente durante su fabricación, y potencialmente peligroso durante el tiempo que la celda solar está en funcionamiento. Adicionalmente el CdS tiene un band gap de Energía $\left(E_{g}\right)$ de $2,4 \mathrm{eV}$ y debido a esto, parte de la radiación incidente en la celda solar es absorbida en la capa buffer ocasionando pérdidas de fotocorriente [4]. En la actualidad fabricar capas buffer libres de Cd que permitan obtener eficiencias elevadas y que no deterioren la estabilidad de la celda solar son algunos de los principales temas de investigación en el área.

En este artículo presentamos aspectos teóricos y experimentales relacionados con la síntesis y funcionamiento de las capas buffer utilizadas en las celdas solares de película delgada. 


\section{Fundamento Teórico}

\subsection{Celda solar de película delgada}

Las celdas solares de película delgada están conformadas por capas de diferentes semiconductores, cuyos espesores varían entre $20 \mathrm{~nm}$ y $5 \mu \mathrm{m}$; el área activa de una celda solar de este tipo presenta un espesor máximo de 7-8 $\mu \mathrm{m}$; debido a esto reciben la denominación de celdas de película delgada. En la figura 1 se presenta el esquema básico de una celda solar de película delgada. Las celdas solares de este tipo son fabricadas de manera estratificada (un material crece encima del otro); estas celdas solares están constituidas por dos contactos eléctricos, la capa absorbente y la ventana óptica que a su vez están conformadas por la capa buffer y un óxido conductor trasnparente. Con el objetivo de reducir las pérdidas de fotocorriente en celdas tipo heterojuntura, estas se fabrican siguiendo un concepto denominado capa absorbente-ventana óptica.

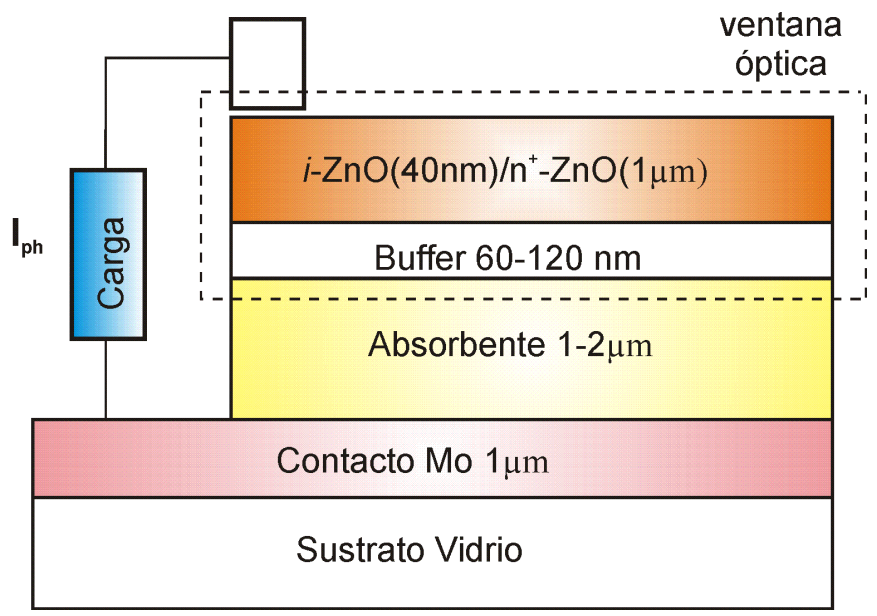

Figura 1. Sección transversal de una celda solar con estructura ventana óptica / capa absorbente.

A continuación se mencionan las principales características de los componentes de la celda solar de película delgada:

La ventana óptica. Está constituida por la capa buffer y la capa TCO y su función principal es facilitar que la mayor cantidad de radiación solar llegue hasta la capa absorbente; además de favorecer la generación de un campo eléctrico intenso en la ZCE del dispositivo, protege la superficie de la capa absorbente durante la deposición del TCO, reduce la cantidad de defectos interfasiales entre la capa absorbente y el TCO mejorando el acople entre las dos capas. Finalmente la capa buffer también reduce procesos interdifusivos desde o hacia 
la capa absorbente; al final la importancia de la capa buffer se ve reflejada en un incremento significativo en la eficiencia de la celda solar [5].

La función de la capa absorbente es absorber la mayor cantidad de radiación solar dentro de la ZCE, con el propósito de generar una alta fotocorriente ya que la presencia del un gran campo eléctrico en la ZCE separará los portadores generados dentro de esta zona para poder generar la fotocorriente y adicionalmente contribuirá a reducir las pérdidas de la misma asociadas a procesos de recombinación en estados de interfase [6].

Los materiales utilizados como ventana óptica deben poseer diferentes propiedades para poder cumplir adecuadamente con la función específica dentro del dispositivo. En particular los materiales que serán utilizados como capa buffer deben ser altamente transparentes a la radiación incidente, deben presentar un $E_{g}$ superior a 2, $4 \mathrm{eV}$ que es el $E_{g}$ que posee el CdS; las capas deben tener espesores del orden de $50 \mathrm{~nm}$ - $150 \mathrm{~nm}$ para que la absorción de radiación sea baja y deben presentar una estructura cristalina definida.

Por su lado las películas delgadas de ZnO que serán utilizadas como parte del TCO deben ser altamente transparentes a la radiación incidente (Transmitancia $\geq 80)$; La capa $\mathrm{n}^{+}-\mathrm{ZnO}$ debe ser altamente conductora $\left(\rho<10^{-3} \Omega \mathrm{cm}\right)$ ya que ésta actúa también como contacto eléctrico superior de la celda; la capa i-ZnO debe ser altamente resistiva $\left(\rho \geq 10^{4} \Omega \mathrm{cm}\right)$ para evitar procesos inter-difusivos.

Capas buffer. Las celdas de película delgada utilizan una película delgada con un espesor entre $50 \mathrm{~nm}-80 \mathrm{~nm}$ en su estructura, esta capa es conocida como capa buffer; la principal función de este recubrimiento es el de mejorar el acople mecánico entre la capa absorbente y el contacto eléctrico superior; en la figura 2 se muestra un esquema de los posibles puntos de desacople mecánico. El acople mecanico entre la capa absorbente y el TCO se ve fuertememnte deteriorado por la presencia de enlaces incompletos y dislocaciones en la interfase de estos dos materiales. Las capas buffer enfrentan dos inconvenientes importantes: (a) el uso de materiales tóxicos para su fabricación lo que acarrea riesgos ambientales durante la fabricación de los recubrimientos; (b) un reducido band gap, inferior a $2,5 \mathrm{eV}$; esto ocasiona que se presenten pérdidas de fotocorriente en longitudes de onda cercanas a la región ultravioleta.

Actualmente la celda solar de película delgada que posee el record mundial en eficiencia de (conversión $20 \%$ [7]), utiliza en su estructura una capa de CdS depositada por CBD como capa buffer; sin embargo, como ya se ha mencionado, el CdS es un material altamente tóxico, además su bajo $E_{g}$ ocasiona que parte de la radiación incidente en la celda solar sea absorbida en la capa buffer produciendo pérdidas de fotocorriente. Por su lado las capas buffer basadas en In y Zn surgen como sustitutos para fabricar celdas solares con capas buffer libres de Cd. Estos compuestos además de no ser tóxicos presentan propiedades estructurales similares a las que presenta el CdS; por su lado las capas buffer basadas en Indio presentan una estructuras cristalinas tipo cúbica y tetragonal; adicionalmente las capas buffer basadas en Zinc presentan estructuras cristalinas tipo cúbica y hexagonal; ambos compuestos como sulfuros tienen un $E_{g}$ superior al que 


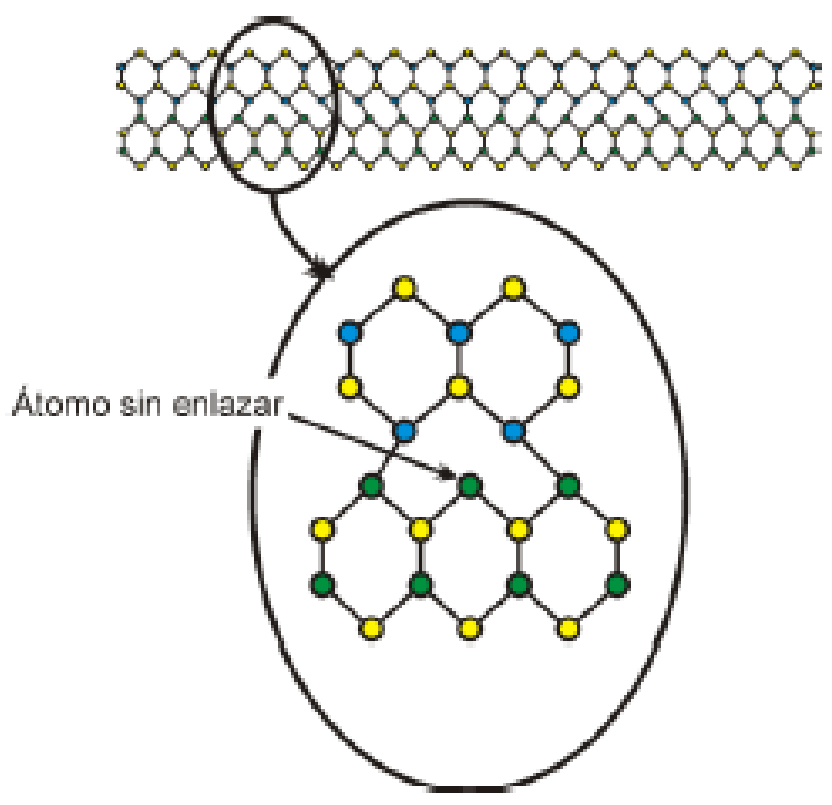

Figura 2. Esquema general de enlaces incompletos en la interfase de dos materiales.

presenta el CdS; esto aumenta la respuesta de la celda a menores longitudes de onda, ocasionando un aumento en la fotocorriente generada por la celda [8].

\subsection{Metodos de síntesis: Chemical Bath Deposition (CBD)}

Las diferentes capas buffer pueden ser fabricadas utilizando diferentes métodos tales como: evaporación térmica, atomic layer deposition (ALD), sulfurización, spputering, metal organic chemical vapor deposition (MOCVD), electrodeposición y CBD $[9,10]$; sin embargo, los mejores resultados en términos de eficiencia y en la actualidad, el proceso CBD es el método de síntesis más utilizado para la síntesis de capas buffer; este método permite depositar películas delgadas de diferentes semiconductores con elevada adherencia, reproducibilidad y uniformidad en los cubrimientos; además los equipos necesarios para su síntesis son de bajo costo, en la figura 3 se muestra un esquema general del reactor CBD [11]. En principio en el método $\mathrm{CBD}$, un sustrato es sumergido en una solución ácida o alcalina, que contiene una fuente del calcogenuro $(\mathrm{S}, \mathrm{Se}, \mathrm{Te})$ y una fuente del metal $(\mathrm{Cd}, \mathrm{Zn}$, $\mathrm{In}, \mathrm{Pb}, \mathrm{Mg}$, etc); para ajustar el $\mathrm{pH}$ de la solución, se utiliza una solución tampón que mantiene el $\mathrm{pH}$ constante durante la formación de la película. Un agente acomplejante es adicionado al medio para controlar la liberación del metal como especie libre. El proceso de formación de la película sobre el sustrato se realiza a 


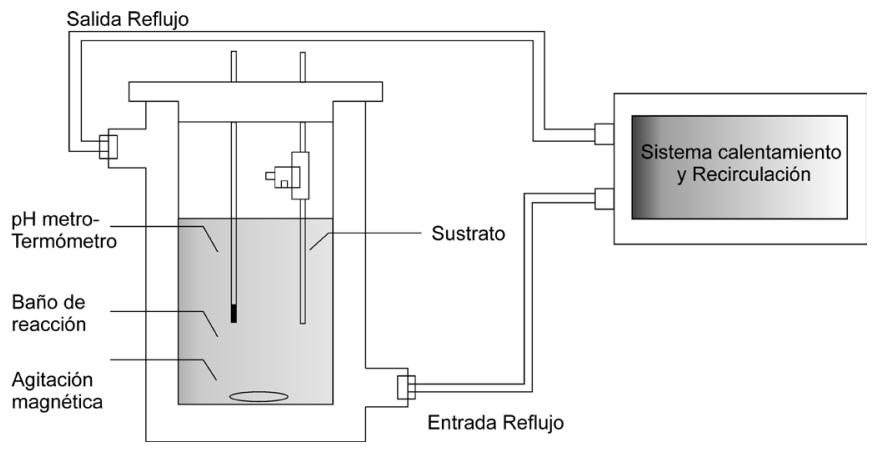

Figura 3. Esquema general del reactor usado para la síntesis de películas delgadas por el método CBD.

través de la precipitación controlada del semiconductor sobre la superficie del sustrato. La precipitación es un proceso que puede ocurrir en fase homogénea (en la solución) o en fase heterogénea (sobre la superficie del sustrato) [12].

Parámetros que afectan el proceso CBD. Es conocido que en el proceso de CBD las características finales de las películas sintetizadas dependen directamente de los parámetros de síntesis, pero son pocos los reportes que explican detalladamente esta dependencia. Al respecto puede decirse que la concentración inicial de los precursores y la temperatura son parámetros experimentales que tienen incidencia directa en la cinética de la reacción; el tiempo de reacción es un parámetro que afecta de forma directa el espesor de la película y la posible cristalinidad de las películas obtenidas. El pH es un parámetro que afecta las especies generadas en solución (complejos y cantidad de sulfuro en solución). Por otra parte, el tipo de sustrato es un parámetro muy importante ya que el proceso de formación de la película ocurre sobre la superficie del sustrato y propiedades como la rugosidad y composición química tendrán un efecto directo sobre la forma como se genera y crece la película.

Crecimiento por CBD. El perfil de crecimiento de cualquier semiconductor utilizando el método CBD sigue un comportamiento típico característico del proceso CBD. En la figura 4 se comparan los perfiles de crecimiento de películas delgadas de $\operatorname{In}(\mathrm{O}, \mathrm{OH}) \mathrm{S}$ sintetizadas por el método $\mathrm{CBD}$ en función del tiempo y el tipo de sustrato utilizado. La figura 4 muestra que para los sustratos utilizados se pueden distinguir dos regiones diferentes; una región denominada 'región de crecimiento lineal' (entre 25-50 minutos de síntesis) y una región de saturación (evidente después de los 60 minutos de síntesis); este tipo de comportamiento es típico en los procesos de crecimiento por CBD. Previo a la zona de crecimiento lineal existe un periodo denominado 'periodo de inducción', este es el paso inicial en el proceso de formación de la película, durante esta etapa, se establecen los 
primeros equilibrios entre las diferentes especies y ocurren los fenómenos de nucleación para la generación de la película. Después del periodo de inducción, se observa la zona de crecimiento lineal, en esta etapa ocurre el crecimiento de los núcleos del semiconductor sintetizado y la película incrementa linealmente su espesor con el tiempo de síntesis; finalmente en la región de saturación la velocidad de crecimiento de las películas disminuye drásticamente debido a la disminución en la concentración de los precursores en el medio de reacción [15].

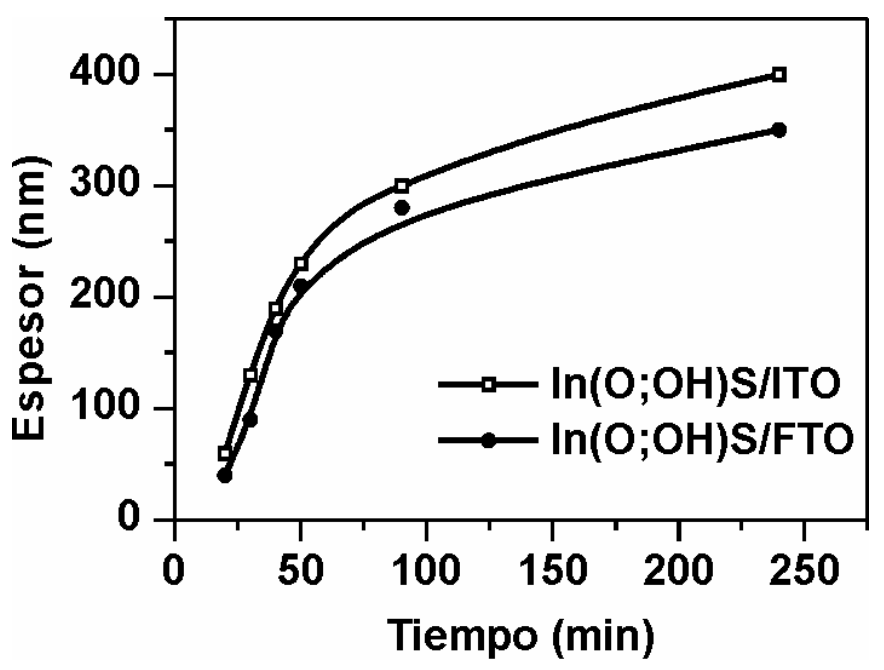

Figura 4. Variación del espesor de películas de $\operatorname{In}(\mathrm{O}, \mathrm{OH}) \mathrm{S}$ depositadas por CBD.

\subsection{Capas buffer libres de Cadmio}

La necesidad de garantizar una fuente de energía totalmente renovable y ecológica exige la eliminación de materiales que sean tóxicos para el ambiente y/o el hombre, es así que se hace necesario garantizar que todos los constituyentes de la celda solar presenten el menor grado de toxicidad posible. Dentro de los materiales tóxicos, diferentes calcogenuros (utilizando azufre o selenio) formando compuestos con Indio, Zinc, Bismuto, Magnesio, en mezclas binarias y/o terciarios, obtenidos por diferentes métodos de síntesis, pueden utilizarse como capas buffer. Compuestos como $\mathrm{In}_{2} \mathrm{~S}_{3}, \mathrm{In}_{2} \mathrm{Se}_{3}$, ZnSe y (Zn,In)Se $\mathrm{x}_{\mathrm{x}}$ sintetizados por diferentes métodos han demostrado su potencial como capa buffer alternativa para remplazar las capas de CdS [16]. El mejor resultado obtenido con celdas solares libres de Cadmio en celdas CIGS utilizando evaporación física se ha reportado para $\operatorname{In}_{2} \mathrm{Se}_{3} \mathrm{y}$ $(\mathrm{Zn}, \mathrm{In}) \mathrm{Se}_{\mathrm{x}}[17,18]$; adicionalmente eficiencias del 15,3\% han sido reportadas con $(\mathrm{Zn}, \mathrm{In}) \mathrm{Se}_{\mathrm{x}}$ depositadas por co-evaporación [19]. Por su lado el El $\mathrm{In}(\mathrm{O} ; \mathrm{OH}) \mathrm{S}$ ya ha 
demostrado su potencial uso como capa buffer alternativa, reportando eficiencias del $15,7 \%$ con celdas solares de $\operatorname{In}_{2} \mathrm{~S}_{3} / \mathrm{Cu}(\mathrm{In}, \mathrm{Ga}) \mathrm{Se}_{2}$ [13,14]. Finalmente la ventana óptica $\mathrm{ZnS}(\mathrm{O}, \mathrm{OH}) / \mathrm{ZnO}$ en celdas solares de CIGS ha reportado la mayor eficiencia en celdas solares libres de Cadmio con 18, $6 \%$ [19].

\section{Perspectivas}

La tecnología de película delgada hizo tránsito con éxito a la etapa de producción industrial gracias a los diferentes desarrollos tecnológicos que generaron a y en la actualidad una celda solar fabricada con estructura ZnO/CdS/CIGS/Mo tiene el record mundial de eficiencia en dispositivos de película delgada a escala de laboratorio, con un 20,1\% de eficiencia. Diferentes desarrollos a escala industrial han permitido la producción en masa de módulos CIGS con 13, $5 \%$ de eficiencia en Showa Shell [20], y módulos de CdTe con 10, 9 \% y $10 \%$ de eficiencia en BP Solarex y First Solar respectivamente [21]. El concepto ventana óptica/capa absorbente le permitió a esta tecnología competir de una manera significativa con las celdas basadas en Silicio; y las capas buffer son uno de los componentes determinantes en la elevada eficiencia de estos dispositivos. Actualmente la búsqueda de nuevos materiales que puedan remplazar los constituyentes tóxicos de estas celdas es uno de los temas de más investigación en el área de la tecnología fotovoltaica. Se espera que los diferentes avances en tecnología de materiales permitan desarrollar nuevas herramientas y métodos de fabricación de semiconductores y seguramente el método CBD seguirá siendo una herramienta muy utilizada a pesar de los desarrollos que se logren debido a su gran versatilidad y facilidades de operación.

\section{Conclusiones}

Actualmente la tecnología de primera generación domina el mercado de las celdas solares, sin embargo la tecnología de película delgada desde hace varias décadas viene presentando un crecimiento significativo que le ha permitido posicionarse como una alternativa económica y novedosa. En este artículo se presentó una revisión de los conceptos referentes a las capas buffer y su gran importancia en las celdas solares de película delgada; adicionalmente se estudiaron conceptos teóricos relacionados con el proceso CBD, el método de síntesis de capas buffer más utilizado en el mundo para la obtención de este tipo de recubrimientos.

\section{Referencias}

1. Renewable Energy Policy Report.: Global Status Report. 2011 Update. P 1-80. (2001)

2. Miles, R., Zoppi, G., Forbers, I.: Mater. Today. 10, 20-28. (2007)

3. Kathleen M., Newham, J.: European Photovoltaic Solar Energy Conference, Glasgow, UK, (2000)

4. Gode, F., Gumus, C., Zor, Ã.M,: J. Cryst. Growth. 299, 136-141 (2007) 
5. Conibeer, G.: Mater. Today. 10. 42-50. (2007)

6. Ben Nasr, T., Kamoun, N., Kanzari, M., Bennaceur, R.: Thin Solid Films 500, 4-8. (2006)

7. Green, M.A., Emery, K., Hishikawa, Y., Warta, W.: Prog. Photovolt: Res. Appl. 17, 85. (2009)

8. Lockhande, C.D., Ennaui, A., Patil, P.S., Giersig, M., Diesner, K., Muller, M., Tributsch, H.: Thin Solid Films. 340, 18. (1999)

9. Ladar, M., Popovici, E., Baldea, I., Grecu, R., Andrea, E.: J. All. comp. 434, 697-700. (2007)

10. Asenjo, B., Chaparro, A.M., Gutiérrez, M.T.: Thin Solid Films 515. 6036-6040. (2007)

11. Naghavi, N., Abou-Ras, D., Allsop, N., Barreau, N., Bücheler, S., Ennaoui, A., Fischer, C., Guillen, C., Hariskos, D., Herrero, J., Klenk, R., Kushiya, K., Lincot, D., Menner, R., Nakada, T., Platzer-Björkman, C., Spiering, S., Tiwari, A.N., Törndahl.: Prog. Photovolt: Res. Appl. (2010)

12. Gangopadhyay, U., Kyunghae Kim, Mangalaraj, D., Junsin Yi.: Appl. Surf. Sci. 230. 364-370. (2004)

13. Hariskos, et al.: A novel cadmium free buffer layerfor $\mathrm{Cu}(\mathrm{In}, \mathrm{Ga}) \mathrm{Se}_{2}$ based solar cells. Sol. Energy Mater. Sol. Cells 41-42, 345-353. (1996)

14. Spiering, et al.: CD-free $\mathrm{Cu}(\mathrm{In}, \mathrm{Ga}) \mathrm{Se}_{2}$ thin-film solar modules withIn $\mathrm{S}_{2} \mathrm{~S}_{3}$ buffer layer by ALCVD. Thin Solid films. 431/432, 359-363. (2003)

15. Hodes, G.: Chemical Solution Deposition of semiconductor films, Marcel Dekker, Inc. New York, (2002)

16. Hariskos, D., Spiering, S., Powalla, M.: Buffer layers in $\mathrm{Cu}(\mathrm{In}, \mathrm{Ga}) \mathrm{Se}_{2}$ solar cells and modules, Thin Solid films 480-481, 99-109 (2005)

17. Ennaoui, A., Siebentritt, S., Lux-Steiner, M.Ch., Riedl, W., Karg, F.: High-efficiency $\mathrm{Cd}$-free CIGS thin film solar cells with solution grown zinc compound buffer layers, Solar Energy Materials and Solar Cells 67, 31. (2001)

18. Chaisitsak, S., Tokita, Y., Miyazaki, H., Mikami, R., Yamada, A., Konagai, M.: Control preferred orientation for $\mathrm{Cu}(\mathrm{In}, \mathrm{Ga}) \mathrm{Se}_{2}$ thin films and its effect on solar cell performance, Proceedings $17^{\text {th }}$ European Photovoltaic Solar Energy Conference, Munich, Germany, pp. 1011. (2001)

19. Contreras, M.A., Nakada, T., Hongo, M., Pudov, O.A., Sites, J.R.: ZnO / $\mathrm{ZnS}(\mathrm{O}, \mathrm{OH}) / \mathrm{Cu}(\mathrm{In}, \mathrm{Ga}) \mathrm{Se}_{2} /$ Mo solar cell with $18.6 \%$ efficiency. $3^{\text {rd }}$ World Conference on Phorovoltaics Energy Conversion, Osaka. Japan (2003)

20. Tanaka, Y., Akema, N., Morishita, T., Okumura, D., Kushiya, K.: Conference Proceedings, $17^{\text {th }}$ EC Photovoltaic Solar Energy Conference, Munich, October 2001; 989-994. (2001)

21. Cunningham, D., Davies, K., Grammond, L., Mopas, E., O'Connor, N., Rubcich, M., Sadeghi, M., Skinner, D., Trumbly, T.: $28^{\text {th }}$ IEEE Photovoltaic Specialists Conference, Alaska, September 2000; 13-18. (2000) 